\title{
Entrevista a Sabina Berman
}

\section{Alfonso Varona}

Sabina Berman Goldberg nació en la Ciudad de México en 1955, hija de inmigrantes polacos. Estudió Psicología y Letras Mexicanas. Es reconocida como una de las dramaturgas más destacadas de Latinoamérica, perteneciente a la generación conocida como la Nueva Dramaturgia Mexicana, la cual comienza a producir a finales de los años setenta y principios de los ochenta. En el ámbito teatral también es directora y productora. Adicionalmente se ha destacado como guionista de cine, periodista, ensayista y novelista.

Ganadora en cuatro ocasiones del Premio Nacional de Teatro (incluyendo en una ocasión la categoría de Teatro Infantil), entre sus obras destacan Bill [Yankee] (1980), Un buen trabajador de piolet [Rompecabezas] (1981), Herejía [En el nombre de Dios] (1984), Águila o sol (1985), Muerte súbita (1988), Entre Villa y una mujer desnuda (1993), Krísis, La grieta (1996), Molière (1998), Feliz nuevo siglo doktor Freud (2000), Extras (2004) y El narco negocia con Dios (2012). ${ }^{1}$

En el 2000 ganó el Premio Nacional de Periodismo por la serie de entrevistas en televisión Mujeres y poder (1999), en colaboración con Denise Maerker e Isabelle Tardan. En 2006 publicó el ensayo Democracia cultural (junto con Lucina Jiménez) y el libro de crónicas sobre el proceso electoral del 2006, Un soplo en el corazón de la patria. En narrativa, ha publicado La bobe (1990), Un grano de arroz (1994), Amante de lo ajeno (1997) y La mujer que buceó dentro del corazón del mundo (2010). Esta última novela ha sido traducida a once idiomas y ganó el premio LiBeratur de Frankfurt en 2012. Desde el 2007 conduce el programa semanal de entrevistas Shalalá en Televisión Azteca.

La presente entrevista tomó lugar en la Ciudad de México el $1^{\circ}$ de julio del 2013. 


\section{Primer acto. Teatro}

¿Qué maestros/as consideras fundamentales en tu formación dramatúrgica? ¿Cuáles consideras tus influencias literarias?

Mis maestros fueron Abraham Oceransky, director de teatro, con quien estudié actuación, y Hugo Argüelles, quien me enseñó teoría dramática y me enseñó a leer los clásicos modernos. Después, uno se forma a través de la lectura de sus autores favoritos y de la observación de la realidad, sobre todo. Yo no soy una autora que vive leyendo libros. Cada vez menos. Me interesa mucho cómo se forman las historias en la realidad. En la realidad humana y en la realidad extrahumana. La naturaleza es una historia viva. Darwin nos enseñó una metodología al respecto. Autores favoritos tengo muchos, pero en teatro los que he estudiado con cuidado son Molière y Shakespeare.

Buena parte de tu obra se caracteriza por la yuxtaposición de personajes históricos con nuestra época y al mismo tiempo por el uso de la parodia y la ironía; esta estética se denomina en la actualidad arte posmoderno. ¿Cuáles son tus objetivos cuando en un texto yuxtapones diferentes temporalidades?

Hay usos muy específicos. En Entre Villa la idea es cómo nuestro machismo contemporáneo es la continuación y la modificación de un machismo más antiguo y más violento y exhibir cómo ese machismo está glorificado (en México, el héroe revolucionario) y cómo en todas las sociedades hay ese héroe macho que está por encima de los vínculos amorosos.

En la última novela que recién acabé, El dios de Darwin, lo uso muchísimo y lo uso para lo mismo, para mostrar la continuidad y la modificación de esa extraña, alucinante, tormentosa y gloriosa capacidad humana que es relatar. Voy mostrando cómo se forman los relatos, cómo el relato cerrado de las religiones nació, cómo opera en nuestros días y cómo opera el relato científico, dónde nació y dónde sobre todo los dos relatos se hicieron enemigos.

Algunos de tus textos teatrales, notablemente Entre Villa y una mujer desnuda $y$ Feliz nuevo siglo doktor Freud, se prestan a un análisis feminista, por hacer hincapié en el desequilibrio del poder entre los géneros. ¿Cuál es tu opinión al respecto?

Sí, a grosso modo estas obras son feministas. Y efectivamente, tratan sobre la desigualdad del poder entre mujeres y hombres. Yo soy feminista radical, pero no soy propagandística. Espero que mis textos trasciendan el momento coyuntural donde están las mujeres y los hombres. Y creo que sí, porque Doktor Freud, ¿de qué trata? De una mujer que se quiere comer el 
mundo. Los adultos, con sus prejuicios, sus enredos y su mala voluntad, se lo impiden a los jóvenes; les destrozan la vida. Pues me he dado cuenta que los hombres jóvenes se identifican igual con el personaje. Tal vez las mujeres más calamitosamente. Espero que eso sea lo que logran mis textos. Entre Villa también, pero es cierto, creo que en la mitad de mis obras, el tema es ése.

En tu carrera como dramaturga a partir de El suplicio del placer (escrita en 1977), hasta Extras (2004) ¿qué textos consideras fundamentales en tu carrera y por qué? ¿Qué obras te han dado mayor satisfacción personal, independientemente del éxito en taquilla?

Entre Villa. Ahí encontré bastante mi voz. Por primera vez, la sentí muy personal y al mismo tiempo me divertí mucho, que eso también es bueno. En lugar de padecerla, empecé a disfrutar hacer teatro.

Molière porque conté una historia más larga, más ambiciosa.

Extras por razones extraliterarias. Pienso que ha sido mi mejor puesta en escena. Recorrimos el país y la vio muchísima gente. La intención era hacer teatro popular en el sentido que lo vieran cientos de personas y que se pudieran conectar, sin perder en belleza estética. Estuvimos en teatros principales, también en campos de fútbol. Era como poner en práctica muchas ideas de Democracia cultural, ponerlas en acción.

Para mí fue importante entrar a la prosa, escribir la novela La mujer que buceó dentro del corazón del mundo.

Satisfacciones, pues yo cuando estoy escribiendo siempre siento satisfacción. Y también siento tormento. Y la satisfacción sí tiene que ver con la influencia que causa un texto en el exterior. Es una segunda mitad del trabajo. En buena medida es el pago que uno recibe por hacer esto. No son las ventas, no es el dinero, es haber contado una historia y haber tocado a otras personas que forman parte de la vida de otras personas, una suerte de inmortalidad horizontal [risa], un rebasar los propios límites, que causa una gran satisfacción.

Es sabido que en 1993 dirigiste Entre Villa y una mujer desnuda por tratarse de un texto que para los productores comerciales resultaba demasiado intelectual y demasiado comercial para los productores del supuesto teatro culto. A veinte años de distancia, ¿ha cambiado esta situación? ¿Crees que de alguna manera Entre Villa abrió el camino hacia una nueva vía en el teatro mexicano (tanto en términos de producción como en estética)?

Lo mismo pasó con Freud. No fui a visitar a los cultos. Los cultos en 
este país son el Estado. No hay productores cultos que vivan de la taquilla. Yo dejé de trabajar con subsidios hace rato.

Sí, [Entre Villa $]$ abrió una nueva vía. Emocionó a muchos teatreros y esa emoción los hizo calcar la manera en que lo hicimos Isabelle Tardan y yo: se buscaron sus productores, también apostaron al teatro mexicano. En esa época era imposible ver en la cartelera comercial una obra de un dramaturgo mexicano. No había tal, jamás. Villa fue un ejemplo de que se podía hacer y cómo, que era utilizando los métodos propagandísticos del teatro nacional, pero en escena mostrando el teatro rigurosamente hecho. Creo que eso tuvo su auge a continuación de Villa y ahora que dejé de escribir varios años teatro y he regresado y me vuelvo a asomar a los teatros, veo que se ha encogido, pero sigue.

Lo que no ha logrado hacer el teatro mexicano es crear una cadena de acontecimientos. Hay obras que sencillamente no pueden viajar. Si tú pones una obra sueca en la cual los problemas de los personajes es que están solos, no puede pasar al teatro comercial porque en este país nadie tiene esa vida, es así como ciencia ficción [risa]. Pero el teatro que sí puede cruzar es el de dramaturgo nacional, [pero] no están esos puentes. Hay más bien una barrera ideológica, cuyos ladrillos son una serie de prejuicios tontos, que no tienen ningún sustento real. Hazme el favor, vivir del subsidio es decente, vivir del público es malo. Son ideas soviéticas, en una era que no existe la Unión Soviética, ni siquiera en China. Es una lástima, nos ha faltado pensamiento propositivo en el conjunto del teatro mexicano. No existe ese eslabón entre los dos teatros y creo que por eso se ha encogido. Al teatro subsidiado, mal llamado culto, yo lo llamaría el teatro arrogante del Estado. Bueno, pero la pregunta era si Villa abrió una nueva vía y yo sí creo que Villa abrió eso.

También significó el regreso del dramaturgo, al ser también el director y el productor. Entonces se puede ser como un pintor, que pinta y tiene control sobre su forma de expresión, un control casi completo. Esa muestra que fue Villa la siguieron varias personas que han hecho largas carreras.

En el verano del año pasado (2012), estrenaste El narco negocia con Dios, la cual reelabora una de las historias de Krísis (1996). ¿Cuál fue tu motivación para retomar dicha anécdota?

La anécdota de cómo sucedió esto es hermosa. Recibo una llamada de una joven universitaria que quiere hacer su examen de graduación como directora montando El gordo, la pájara y el narco [texto que asimismo sirvió de base a Krisis]. Ese texto se me había olvidado; ella lo encontró editado por la Universidad de Aguascalientes. Le digo "sí, móntalo, pero te pido un 
favor. Mándamelo en formato digital para leerlo". Yo no tenía una copia. Me lo llevé impreso en un viaje de avión. Empecé a tener ataques de risa, al grado que la azafata llegó a preguntarme si estaba teniendo un ataque de algo [risa]. Cuando bajé del avión le hablé a Ana Francis Mor, directora y actriz de las Reinas Chulas. Ella me había insistido "Sabina, regresa al teatro". Y yo le decía "sí, voy a regresar, pero no sé cómo exactamente" porque sabía que si regresaba al teatro, iba a regresar para siempre y a ir dejando todo lo demás. Le dije "voy a regresar al teatro, pero dirígelo tú" y se lo mandé. Coincidimos en hacerlo en un teatro chico, sin ninguna presunción. No tuve nada que ver en la producción. Fui al teatro y corregí algunas veces sobre escena. Tenía una gran curiosidad porque Krísis fue la única obra que casi fue un fracaso. La explicación que nos dimos era que la gente no quiere ver la realidad cuando es tremenda. Con El narco me sorprendió gratamente ver a gente desternillándose. Hay un tabú en México y en general en Occidente de reírse de la religión descaradamente. Aquí es una carcajada al sistema de valores religiosos, pero también al sistema de valores liberales. Esto de "yo soy para mí mismo", "yo soy libre". Como siempre en las comedias que funcionan, la gente se ríe más de lo que suponías, porque la risa se vuelve una cosa ya orgánica. Gocé muchísimo de ver las carcajadas de la gente. Fui

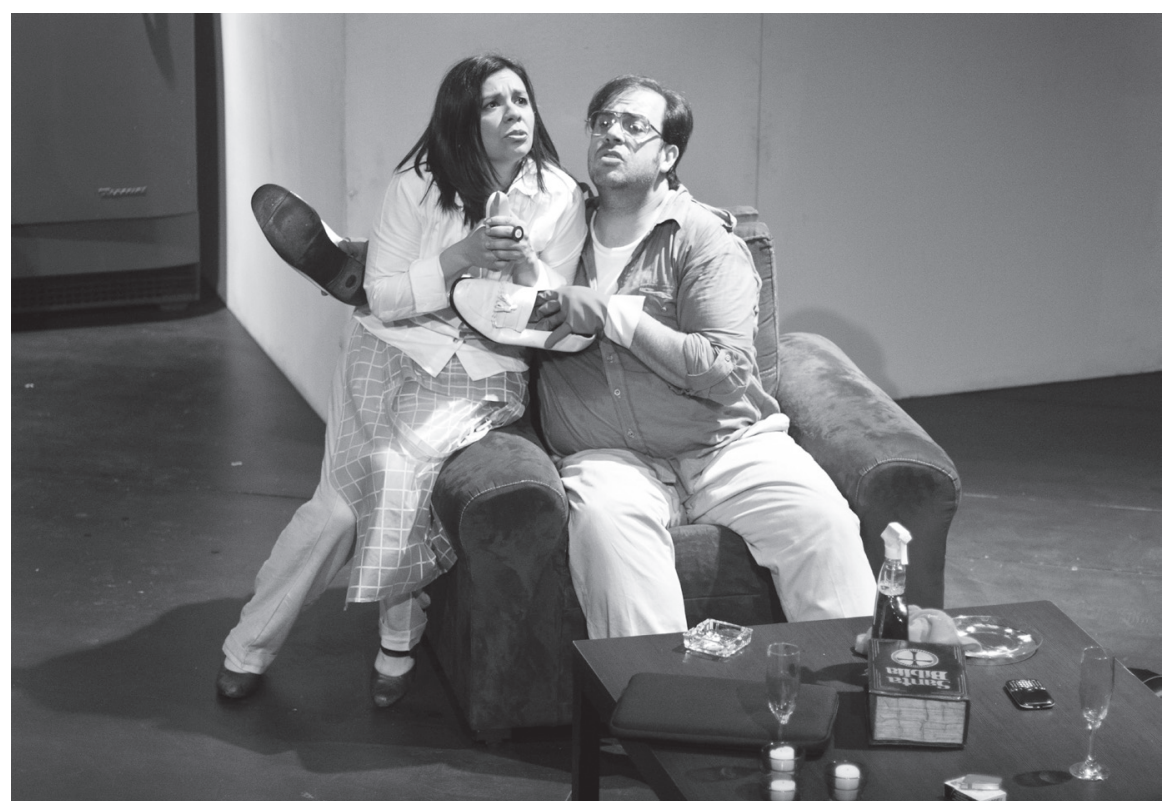

El narco negocia con Dios. Foto: Foro Shakespeare. 


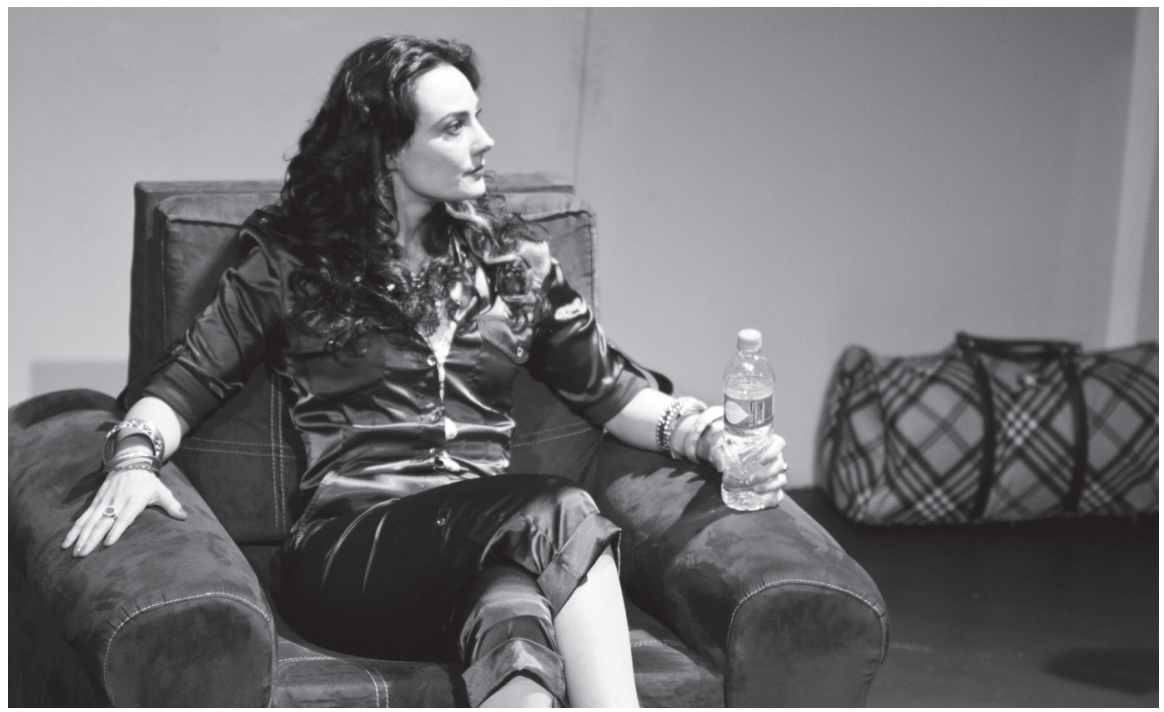

El narco negocia con Dios. Foto: Foro Shakespeare.

mucho a esas funciones porque para mí era el regreso al teatro, entonces tenía que volverme a recordar dónde estaba el músculo del teatro.

También, [es increíble que] algo que había escrito como farsa, diez años después se volviera realismo y que tocara uno de mis temas personales más importantes y un tema que está ausente de la discusión en México, que a mí me enerva que esté ausente, que es la moral. Cuando en México hablamos de moral, generalmente la gente se refiere a la moral judeocristiana. Ni siquiera hay una claridad en cuanto qué es la moral y de eso se trataba el texto.

Por la abierta crítica al PRI (Partido Revolucionario Institucional), Krísis no pudo ser publicitada, puesto que los medios masivos no querían problemas con el gobierno. El narco negocia con Dios se estrena al final del gobierno de Calderón, del PAN (Partido Acción Nacional), en el contexto de "La guerra contra el narco". ¿Te encontraste con una situación similar a la de Krísis? La obra fue anunciada en los medios y presentada en el Foro Shakespeare.

En el interior de la república definitivamente no pudimos viajar con la obra. La gente no se la quería llevar, les daba miedo que los narcos hicieran algo al respecto de la obra. Salimos a unas cuantas partes. Cuando fuimos creo que a Puebla, el día antes de la función los empresarios dijeron "no podemos sacar en el periódico ese título, dennos otro" y yo le puse "El naco negocia con dos", confiada en que la gente conocía el título. 
En el DF no hubo problema. Si hubiera sido la productora, les hubiera insistido a los empresarios lo que estaba pasando: llegaban narcos y se partían de la risa. Estaba anunciada en un blog que los narcos consultan para ver cómo están sus cosas. Los narcos se reconocían en la obra, estaban bien retratados, así como son. De repente llegaban tipos que ni siquiera disimulaban y el público se daba cuenta.

Es muy raro, porque el narco habla expresamente de matar gente y la gente se reía. Había partes donde yo no me reía al escribirlo y sí me sorprendió el público mexicano.

Acabo de ver el reestreno de Feliz nuevo siglo doktor Freud, dirigida por Alberto Lomnitz ¿Cómo surgió la idea de montar de nuevo esta obra? ¿Participaste en este proyecto? ¿Y has visto la puesta?

Me llamaron para pedirme los derechos y me dijeron que querían escenificar una obra mía y que querían que fuera Feliz nuevo siglo doktor Freud. Y entonces dije “¿Por qué esa obra?” [y me dijeron] "Pues porque uno de nosotros, una joven, se dedica a hacer teatro exclusivamente porque vio esa obra". Es una producción muy sencilla. El director es muy bueno, Alberto Lomnitz, y el resultado es una puesta que la gente goza. Alberto hizo que el texto sonara muy claro y muy sencillo. Los actores son muy buenos también.

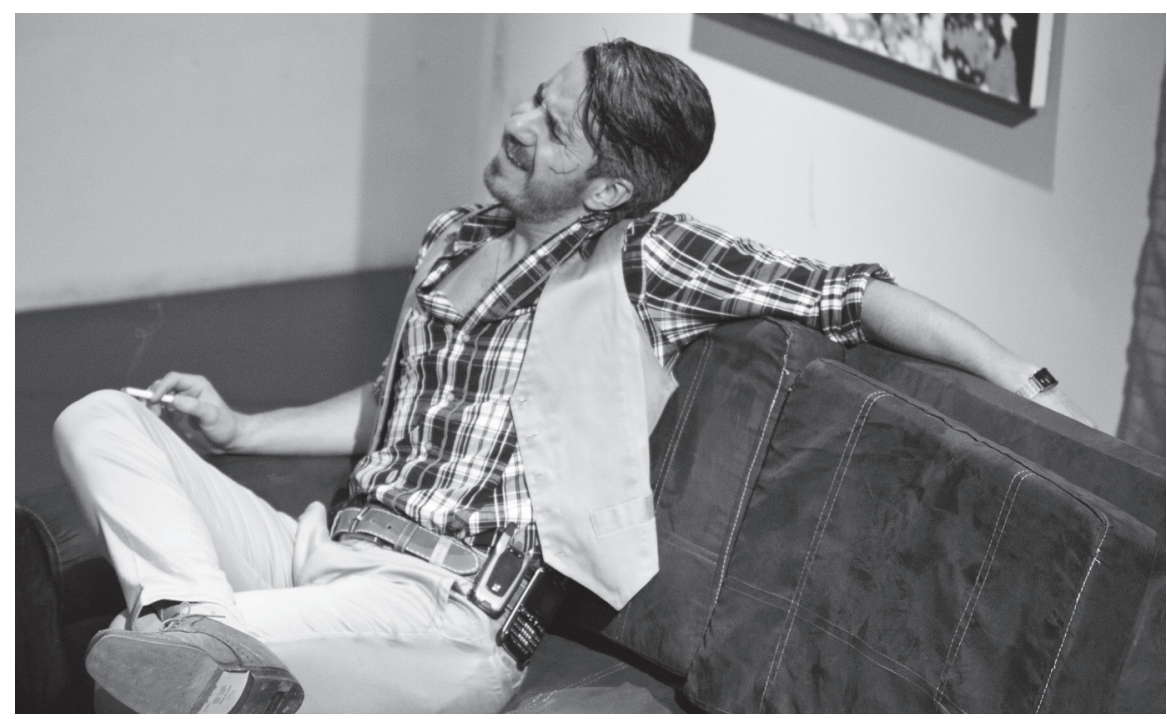

El narco negocia con Dios. Foto: Foro Shakespeare. 


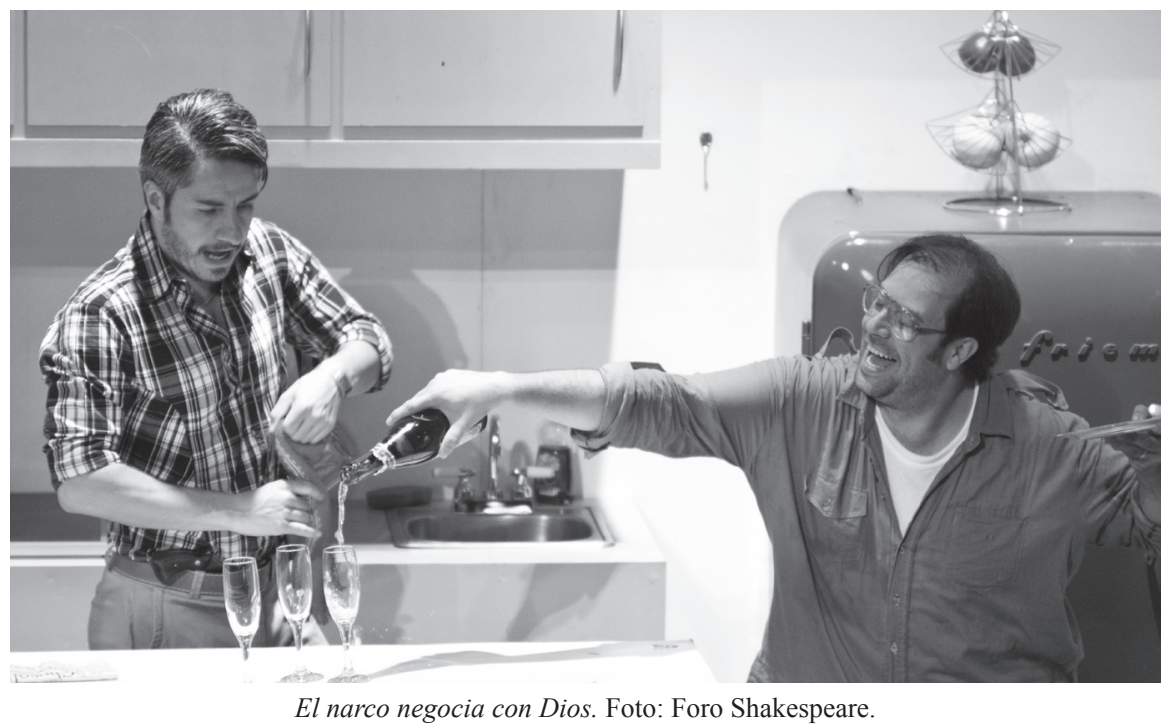

De tus obras estrenadas en el extranjero ¿Qué montajes han sido los más memorables, en tu opinión?

Molière. En Toronto tuvo un muy buen montaje. El año pasado en Nueva York se hicieron algunas funciones "off off Brodway" que me dieron muchísimo gusto porque era así como "bare bones production", estaban bien montadas, extraordinariamente bien actuadas. Creo que porque es la más atractiva para alguien que no sea latinoamericano. Es la más abierta. Doktor Freud también lo podría hacer, pero no se ha montado en el extranjero.

\section{Segundo acto. "La realidad": Periodismo, etc.}

La serie de entrevistas Mujeres y poder (1999), que llevaste a cabo con Denise Maerker e Isabelle Tardan en el canal 11, ganó el Premio Nacional de Periodismo en el 2000. Mi percepción es que a partir de esta época comienzas una nueva etapa en tu carrera, que te lleva a escribir más y más directamente sobre la "realidad", sin la mediación de ésta con la creación literaria. Pienso especificamente en la versión en libro de Mujeres y poder, las crónicas de Un soplo en el corazón de la patria y el programa Shalalá que conduces en Televisión Azteca. ¿Cuáles fueron tus motivaciones para abordar el periodismo y cómo te iniciaste en éste?

Mi motivación fue que en México estábamos pasando de una "dictablanda" a una democracia. Era muy emocionante y me involucré en ese cambio. Teníamos la sensación de que íbamos a cambiar [el país] y lo cam- 
biamos, no tanto como hubiéramos querido, ni con tanta influencia como hubiéramos querido. Eso fue lo que me atrajo.

A partir del año 2007 comienza tu programa semanal de entrevistas que mencioné en la pregunta anterior. ¿Cómo surge la idea de este proyecto? ¿Qué satisfacciones te ha dado esta labor?

Surge de una invitación de la televisora. Al principio me pasmó la idea de estar dentro del escenario, pero muy rápido se me quitó el pasmo y dije "qué gran oportunidad, poder invitar a la gente que le causa a uno una curiosidad y poderle preguntar lo que además socialmente jamás le podría uno preguntar". Y venía, claro, de eso que uno puede influenciar la realidad de su propio país. Y complementariamente, de la curiosidad de cómo se cuentan las historias sociales de un país. ¿Qué se pregunta y qué no se pregunta? El tema de las entrevistas en ese momento en México era: ¿Qué tan transa eres? ¿Qué tanto nos engañaste, qué tanto te robaste, qué tanto eres un mentiroso? Y pensé: "Ahí es donde tengo otras preguntas. Y tengo otros invitados" y esa era la novedad de Shalalá, otras preguntas y otros invitados: gente de la sociedad civil, no sólo gente que está en los lugares políticos donde se maneja el poder. También temas, en lugar de personajes.

Por ejemplo, yo creo que en Shalalá fue la primera vez que en un programa de televisión abierta hubo transgéneros, además con una enorme franqueza. He hecho tres programas con transgéneros y en uno hablamos de cómo se realiza el coito, de cómo es la operación, o sea, llegar a un relato adulto y completo de una experiencia tan del siglo XXI como la transexualidad que me parece una de las grandes señales de nuestra época. ¿Qué diablos estamos pensando? Hay que ver a los transexuales, que creen que pueden cambiar de género sexual y que si nacieron sin tetas se las ponen... Para entender nuestra época, los transexuales son claves. Por ejemplo, eso en un programa político, teóricamente no es político, pero claro que es político. Ahí mi feminismo, donde lo privado es público, influyó mucho. Yo en general estoy más interesada que el término medio de los reporteros en la sociedad civil.

[Otro ejemplo,] si hay policías comunitarios que surgen en la costa chica de Guerrero y echan de sus pueblos a la policía, nosotros mandamos a un helicóptero para traernos a estos policías y aunque los policías llegaron enmascarados, a la mera hora se decidieron quitar las máscaras, ese fue uno de los programas emocionantes que hicimos hace poco y le dimos una hora a esa gente de Guerrero para que nos contaran por qué se levantaron en armas y corrieron a sus policías locales. Imagínate, a mí como dramaturga, estos 
sucesos rebasan completamente mi imaginación. Y al ser contados se vuelven parte de mi riqueza de historias y de las del público. Yo le repito muchísimo al equipo de Shalalá que no estamos necesariamente detrás de la noticia. Si hacemos noticia además, qué bueno, pero a menudo no estamos detrás de la noticia, estamos detrás de la historia.

En tu ensayo Democracia cultural, identificas el absurdo en México de un apoyo monetario real (y con resultados contundentes) a los jóvenes creadores, pero desligado por completo de la sociedad y el turismo, desperdiciándose así una producción cultural que enriquecería a la sociedad mexicana (tanto espiritual como monetariamente). En tu opinión, ¿se ha dado algún avance significativo en este renglón, por parte del gobierno federal?

No, el modelo de apoyo al arte no ha cambiado en México en los últimos dieciocho años. Una y otra vez se invierte en los artistas y su arte y no se tienden puentes con la sociedad. El resultado se cifra en estos números. En 1990, uno de cada 10 mexicanos había asistido en un año a un evento cultural. Hoy, luego de miles de cientos de millones de pesos y de esfuerzo invertido en el arte, la cifra ¡es idéntica! Lo que significa también que fuera del apoyo del Estado casi no hay productores particulares.

\section{Tercer acto. Narrativa y cine}

Has publicado cuatro libros de narrativa entre 1990 y 2010. Tu última novela, La mujer que buceó dentro del corazón del mundo, ha sido traducida a varios idiomas. Es una historia fascinante y bien lograda de una niña autista que gracias al amor y tutela ilustrada de su tía triunfa como empresaria atunera. ¿Cómo surge la idea para desarrollar esta historia?

Empezó buceando. Estaba buceando y pensé, "este estado de máxima alerta, de supra conexión con el exterior del cuerpo, me gustaría tenerlo todo el tiempo”. Entonces dije, “qué me estorba?” Es el lenguaje. El lenguaje te hace alucinar todo el tiempo, te interpone entre la realidad y tu cuerpo otra realidad sucedida en otro momento o que podría suceder en otro momento. De eso, de ese darme cuenta. No sé por qué tuve la seguridad que el autismo es una experiencia semejante. Yo había trabajado con autistas y con niños con síndrome de Down cuando estudié psicología. Pero además no importa, no es un libro médico.

Tu actividad en la narrativa la veo como un puente entre tu etapa predominantemente dramatúrgica y la periodística. ¿Qué importancia tiene para ti en este momento la narrativa? 
Yo fui educada en el teatro en una época donde uno de los prejuicios es que los textos deberían ser breves y casi monosilábicos, un teatro paupérrimo en cuanto a expresión verbal y donde además los personajes no saben nada. Beckett es el extremo. Al escribir narrativa, me tuve que educar en un terreno donde el lenguaje sí dice y puede decir largamente y puede decir de manera importante. En la dramaturgia previa, esta monosilábica que todavía es como síntoma general en el teatro, los personajes no se atreven a afirmar sobre la realidad grandes cosas, acaso sobre su familia. Casi no afirman y viene de una falta de fe en el lenguaje. No es accidental que sea el momento en donde como cultura nos damos cuenta de que todas las historias son ficción, pero creo que estamos entrando a otra época, por lo menos personalmente yo sí estoy entrando a donde dices: "OK, todo es ficción, pero vamos a elegir las ficciones que van a regir nuestras vidas. Tengamos confianza en el lenguaje, como lo que es, no como nuestros abuelos creían que era". En El narco negocia con Dios es bastante claro. Es una obra de personajes sentados platicando. Y creo que no se nota. Son cuatro personas que no hacen otra cosa más que hablar. La única acción dramática es que alguien se cae por una ventana y después que alguien mata a otra persona. Fuera de eso no hay ninguna acción dramática. Y la obra que voy a estrenar en enero [de 2014], peor, son dos personas en un sofá platicando. Yo espero que no vaya a ser aburrida. Pero regresar a la confianza del lenguaje, no de que el lenguaje es la realidad. El lenguaje es una cosa y la realidad otra.

Te digo más, yo vi textos que cambiaron la historia de un país, los vi suceder y cuando ves eso, es cuando te vienen estas ideas, qué importante es saber lo que puede provocar el lenguaje. Para dar un ejemplo, la democracia en México entra por una sola respuesta en un debate. Ese texto ganó la presidencia a la oposición en un país donde todo el sistema electoral y sobre todo la estructura de los sindicatos, todo esto que aglutina a millones de personas, estaba dominada por un partido. Imagínate que una buena respuesta en un debate hace que se caiga todo. Todos sabíamos esa respuesta "Ustedes son unos tramposos", pero nadie lo había dicho en la tele. En ese momento cambia un país.

No quiero pasar por alto mencionar la película Backyard: El traspatio (2009), sobre los asesinatos de mujeres en Ciudad Juárez, documentados a partir de 1993. El guión, publicado originalmente en 2005, obtuvo premios en festivales de cine en La Habana y Cataluña. ¿Cuál fue el proceso de investigación que seguiste para escribir esta historia, que aunque ficticia tiene el rigor y la estética realista de un documental? 


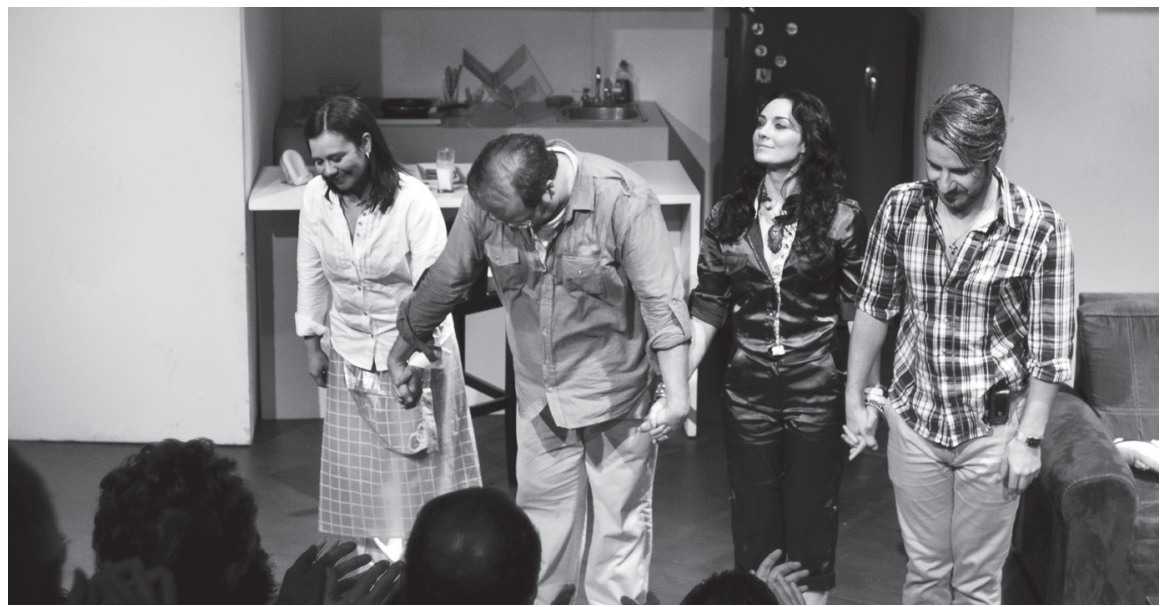

El narco negocia con Dios. Foto: Foro Shakespeare.

Fui a los lugares específicos y hablé con la gente afectada. De hecho la película se filmó en los lugares reales. Se nos metió la realidad muy fuerte [pues la actriz principal fue amenazada de muerte]. Los policías que salen ahí no son extras, son los que estaban ahí.

\section{Epílogo}

¿Cuáles son tus planes futuros?

Yo voy a escribir mucho teatro. Yo quiero hacer teatro. Me fui fácil 10 años ¿no? y mi intención es seguir en el teatro.

¿Cómo entra eso con la narrativa y la televisión?

Yo creo que se van a volver secundarios. No sé si voy a seguir o no, pero me doy cuenta que disfruto muchísimo el teatro.

Muchas gracias por la entrevista.

[Telón]

Hampden-Sydney College, Virginia

\section{Notas}

1 Todas las fechas de las obras teatrales son las del estreno a menos que se indique de otra manera. 